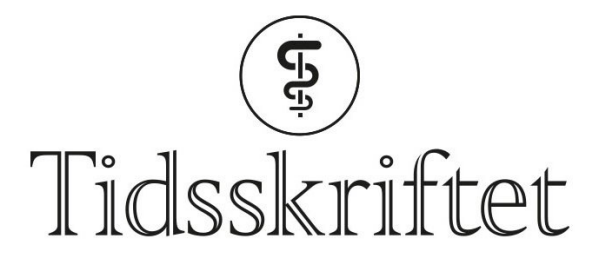

DEN NORSKE LEGEFORENING

\title{
Forkalkning i kjeveligament
}

MEDISINEN I BILDER

\section{KATHRINE GRøNNING ARNTZEN}

E-post: kathrine.arntzen@nordlandssykehuset.no

Kathrine Grønning Arntzen (f. 1986) er lege i spesialisering ved Nevrologisk avdeling, Nordlandssykehuset Bodø.

Forfatter har fylt ut ICMJE-skjemaet og oppgir ingen interessekonflikter.

\section{PAULINA DOROTA SLOWINSKA}

Paulina Dorota Slowinska (f. 1967) er spesialist i nevrologi ved Medisinsk avdeling, Helgelandssykehuset Mosjøen.

Forfatter har fylt ut ICMJE-skjemaet og oppgir ingen interessekonflikter.

\section{FRANCIS ODEH}

Francis Odeh (f. 1971) er ph.d. og spesialist i nevrologi ved Nevrologisk avdeling, Nordlandssykehuset Bodø.

Forfatter har fylt ut ICMJE-skjemaet og oppgir ingen interessekonflikter.

Eagles syndrom, også kjent som stylalgia, er en sjelden smertetilstand assosiert med en elongert processus styloideus eller forkalket ligamentum stylohyoideum.

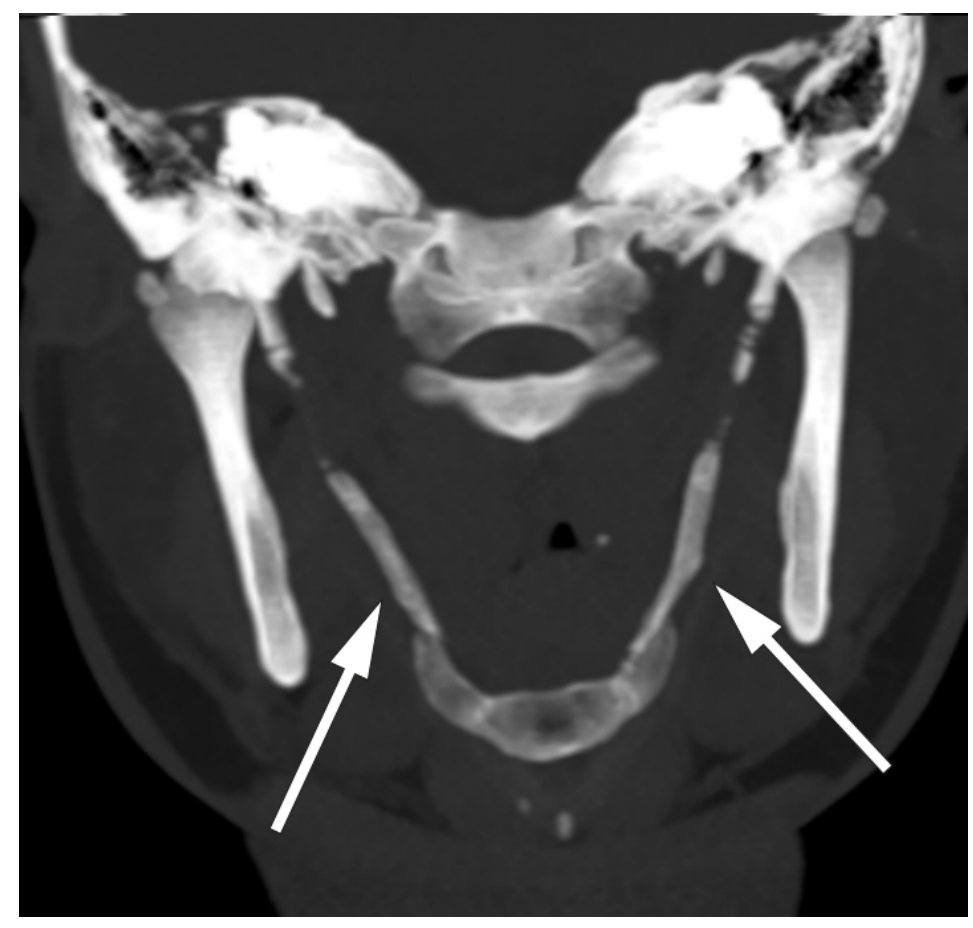




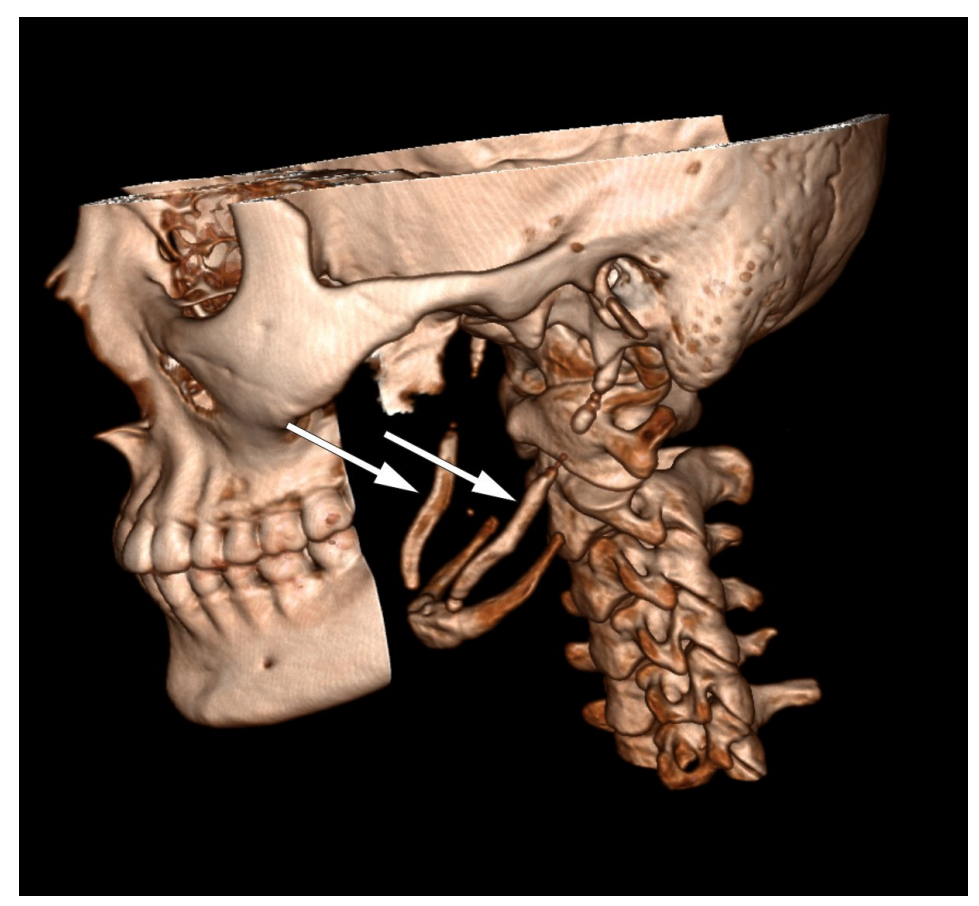

En tidligere frisk kvinne i 30-årene utviklet en paroksysmal, smertefull og krampaktig fornemmelse i venstre halvdel av nakke, svelg og ansikt med ledsagende global hodepine og ipsilateral tinnitus. Hun hadde også smerter og nummenhetsfornemmelse i den ipsilaterale delen av tungen, men ikke hørselstap, dysfagi eller dysfoni. Plagene debuterte etter trening med repetitiv vektløfting.

Symptomene ble fremprovosert og forverret med sidebøy og rotasjon av hodet mot høyre. Anamnestisk hadde hun hatt en lignende og forbigående episode to år tidligere. Det var ikke noe hode- eller nakketraume i sykehistorien. Klinisk undersøkelse var upåfallende, foruten palpasjonsømhet peritonsillært og over venstre nakkehalvdel. Omfattende utredning med nevrofysiologiske, bildediagnostiske og øre-nese-hals-unders økelser viste normale funn. CT-undersøkelse av nakken avdekket forkalkning i ligamentum stylohyoideum bilateralt (se piler), noe som kunne forklare pasientens symptomer.

Eagles syndrom kategoriseres som enten ervervet eller medfødt, men etiologien er ennå uavklart. Processus styloideus er forlenget (>30 $\mathrm{mm}$ ) hos omtrent $4 \%$ av befolkningen. Prevalensen varierer imidlertid en del, og bare et lite fătall (1-5\%) av disse utvikler symptomer som kan relateres til funnet (1).

Tilstanden presenterer seg ofte med unilateral orofacial-cervikal smerte og dysfagi. Symptomene skyldes kompresjon av nærliggende strukturer som chorda tympani, n. auriculotemporalis, n. lingualis, n. glossopharyngeus og n. hypoglossus. En sjelden gang kan processus styloideus komprimere arteria carotis interna og føre til nevrologiske symptomer som svimmelhet og transitorisk iskemisk anfall. Tilstanden kan også føre til carotisdisseksjon og Horners syndrom (1), men dette er svært sjeldent. CT-undersøkelse er gullstandard når det gjelder diagnostikken (1). Aktuelle differensialdiagnoser er temporomandibulær dysfunksjon, smerter i visdomstann, glossopharyngeus- og trigeminusnevralgi, migrene, cervikal artritt, hyoid bursitt, temporalisarteritt, klasehodepine (cluster), myofascielt smertesyndrom, parafaryngeale, romoppfyllende lesjoner og sekvele etter tonsillektomi.

Behandlingen er enten konservativ med medikamentell tilnærming (NSAID-preparater, antiepileptika og/eller antidepressiver), som vi valgte hos vår pasient, eller kirurgi ved refraktære tilfeller. Syndromet bør alltid vurderes hos pasienter med kroniske orofaciale smerter, som er refraktære til konvensjonell behandling. 
1. Badhey A, Jategaonkar A, Anglin Kovacs AJ et al. Eagle syndrome: A comprehensive review. Clin Neurol Neurosurg 2017; 159:34 - 8. [PubMed][CrossRef]

Publisert:14. august 2018. Tidsskr Nor Legeforen. DOI:10.4045/tidsskr.17.0923 Mottatt 25.10.2017, første revisjon innsendt 28.3.2018, godkjent 18.5.2018.

(C) Tidsskrift for Den norske legeforening 2020. Lastet ned fra tidsskriftet.no 